\title{
"PUBLIQUE OU PEREÇA": EFEITOS DO PRODUTIVISMO ACADÊMICO NA PRODUÇÃO EM PERIÓDICOS DE UM PROGRAMA DE PÓS-GRADUAÇÃO EM EDUCAÇÃO (2000-2018)
}

\author{
Matheus Estevão Ferreira da Silva \\ Universidade Estadual Paulista Júlio de Mesquita Filho (UNESP), Maŕlia, São \\ Paulo, Brasil
}

\begin{abstract}
Resumo: Neste artigo, por meio de revisão bibliográfica, investigam-se os possíveis efeitos gerados pelo produtivismo acadêmico na produção em periódicos de um Programa de Pós-Graduação em Educação. Considerou-se o estado atual da produção de pesquisa brasileira, que tende a aderir ao produtivismo acadêmico e à formação do(a) pesquisador(a) em detrimento da formação do(a) professor(a) universitário(a). Delimitou-se a investigação elegendo, pelos critérios definidos, um Programa de Pós-Graduação da área de Educação com conceito CAPES acima de 4 e, para se medir os efeitos do produtivismo, levantou-se a produção em periódicos do corpo docente desse Programa, considerando-se o período de 2000 a 2018. Depreendem-se, de fato, efeitos na produção do Programa, com um aumento muito significativo que se relaciona com a submissão à política da CAPES na avaliação da pós-graduação.
\end{abstract}

Palavras-chave: Produtivismo. Pós-Graduação. Produção acadêmica.

INTRODUÇÃO

No sistema universitário brasileiro, a política de financiamento de bolsas de iniciação científica, de bolsas de pós-graduação e de projetos de pesquisa se baseia no conhecido ditado 'Publique ou pereça!' (Publish or perish!) das universidades americanas. Essa pressão para escrever e publicar tem levado alunos, professores e pesquisadores universitários a um esforço concentrado na elaboração de textos de qualidade na forma de artigos para periódicos acadêmicos e livros para editoras como meio de assegurar espaço profissional. Desse modo, na cultura acadêmica, a produtividade intelectual é medida pela produtividade na publicação. Por muito tempo, diferentes áreas questionaram o valor de uma política de publicação pautada pela quantidade em detrimento de uma análise mais atenta da qualidade das publicações. Mas, para mudar o sistema, é preciso conhecê-lo e partir dele. 
Désirée Motta-Roth e Graciela Rabuske Hendges (2010, p. 3, grifos das autoras) iniciam seu livro Produção textual na universidade com as palavras dispostas na citação acima. Embora o foco do livro seja a orientação para a produção textual acadêmica, a primeira manifestação, em seu conteúdo, trata-se desse alerta para o estado que a produção de pesquisa brasileira se encontra atualmente.

Nas últimas décadas, sob a influência direta e indireta de políticas neoliberais, a avaliação em geral tomou rumos diferentes dos até então conhecidos, voltando-se para um mecanismo de regulação e controle excessivo e, por vezes, abusivo', e isso em diferentes esferas de ação "organizada de sujeitos, instituições e governos, incluindo políticas educacionais e científicas. A pesquisa científica [... é] também afetada por sistemas de avaliação padronizada, com objetivo de monitorar (regular e controlar) a produção de conhecimento" (MORTATTI, 2019, p. 11). No âmbito acadêmico, desse novo mecanismo de avaliação, nasce o chamado "produtivismo acadêmico".

Outra problemática, provinda do mesmo mecanismo, refere-se à responsabilidade atribuída aos cursos de pós-graduação stricto sensu de formar professores(as) universitários(as), mas que têm se concentrado em formar apenas para a pesquisa, abstendo-se da

\footnotetext{
formação didático-pedagógica das novas gerações de mestres e doutores. Logo, a formação docente não é uma prioridade, pois essa não é [...] um critério de avaliação do desempenho das instituições de ensino superior. As avaliações estão voltadas ao número de patentes, pesquisas e publicações ou ao grau de internacionalização (VOSGERAU; ORLANDO; MEYER, 2017, p. 233).
}

As investigações e críticas que se encontram na literatura a respeito da avaliação da pósgraduação no Brasil, bem como dos efeitos do produtivismo acadêmico, embora consideráveis, são escassas em levantamento de dados. Este artigo foi produzido diante desta lacuna, procurando preenchê-la, ainda que para isso outras iniciativas como esta sejam necessárias. Portanto, ele se junta a essa literatura de "avaliação da avaliação", buscando analisar de forma crítica os critérios atuais de avaliação da produção de pesquisa da pós-graduação brasileira.

Considerando-se esse referido estado atual, em que se tende a aderir ao produtivismo acadêmico e à formação do(a) pesquisador(a) em detrimento da formação do(a) professor(a) universitário(a), duas delimitações foram aplicadas para viabilizar a investigação proposta sobre os efeitos do produtivismo. Primeiro, elegeu-se um Programa de Pós-Graduação (PPG) pelos seguintes critérios: a) Programa da área de Educação; e b) Programa com conceito CAPES acima de 4 que, além de buscar a formação em pesquisa, apresente uma "[...] importante finalidade ao acolher professores universitários de diferentes áreas e oferecer-lhes a formação para a docência" (VOSGERAU; ORLANDO; MEYER, 2017, p. 233). Segundo, da produção do PPG eleito, enfocou-se apenas artigos publicados em periódicos, mesmo tendo em vista que há vários outros possíveis veículos de divulgação de resultados de pesquisa.

Logo, neste artigo apresentam-se os resultados de uma pesquisa que objetivou investigar os possíveis efeitos gerados pelo produtivismo acadêmico na produção em periódicos de um Programa de Pós-Graduação em Educação. Para se medir os efeitos do 
produtivismo, procurou-se levantar as publicações em periódicos do corpo docente desse Programa, considerando o período de 2000 a 2018.

Por questões éticas, deixou-se em anonimato o nome da Universidade que teve seu Programa de Pós-Graduação eleito para participar da pesquisa, bastando saber que se trata de um Programa da área de Educação e com conceito CAPES (Coordenação de Aperfeiçoamento de Pessoal de Nível Superior) acima da média (a saber, acima do conceito 4 , considerado entre bom e mediano) $)^{2}$.

Pôde-se constatar que, de fato, depreendem-se efeitos na produção do Programa investigado, com um aumento muito significativo da publicação de artigos em periódicos e que se relaciona temporalmente com a legitimação da CAPES como responsável pela avaliação da pós-graduação e a instauração de uma política de avaliação "quantitativa da qualidade", conforme expõe-se a seguir.

\section{O(S) ATUAL(IS) PROBLEMA(S) DO PRODUTIVISMO ACADÊMICO}

A CAPES, inicialmente sob o nome de Campanha de Aperfeiçoamento de Pessoal do Ensino Superior, foi criada em 1951 com a incumbência de suprir a formação de docentes a atuarem na Educação Superior, com vistas a erradicação de docentes não titulados que, desde então, atuavam em Instituições de Ensino Superior (IES) no país (KUENZER; MORAES, 2005). Com o passar dos anos, contudo, as atribuições da CAPES foram se transformando de acordo com demandas econômicas e estruturantes do sistema educacional brasileiro.

Dessas transformações, cita-se a relevância que a instituição passou a dar à pesquisa na pós-graduação stricto sensu, privilegiando-a em detrimento de sua incumbência anterior e primária de formação de professores(as) para a Educação Superior. Com isso, mudanças também puderam ser vistas na estrutura e na política de avaliação dos Programas de Pós-Graduação, também passando-se a valorizar a produção científica, tais como:

\footnotetext{
[...] a diminuição do prazo para defesa; as alterações nas exigências para credenciamento de professores e avaliação dos programas, impactando, também, diretamente, os critérios adotados por órgãos de fomentos para financiamento de pesquisa e concessão de bolsas e os critérios adotados em concursos públicos para docência no ensino superior em instituições públicas (SILVA; GONÇALVES-SILVA; MOREIRA, 2014, p. 1424).
}

Diante disso, pesquisadores(as) têm se preocupado em alertar sobre os problemas que essa nova política, intermediada pela CAPES, pode trazer (e já trouxe) para a formação docente de mestres e doutores, além de seu impacto na rotina de trabalho e saúde de todos os sujeitos envolvidos com a pesquisa acadêmica.

Paiva (2016) investigou as transformações do trabalho docente em dez cursos de pós-graduação stricto sensu. A pesquisa revelou que os(as) docentes atuam tanto na graduação quanto na pós-graduação (mestrado e doutorado), levam trabalho para casa a fim de conseguirem cumprir integralmente suas atribuições rotineiras e que a produção - valorizando-se a quantidade em detrimento da qualidade na produção de artigos - é quase obrigatória para mantê-los nos Programas. 
Salvá (2015) também analisou as transformações ocorridas no trabalho docente junto a um PPG stricto sensu. Verificou-se que, face à implementação dos critérios da CAPES de avaliação, as transformações materializam-se no produtivismo acadêmico, o que acarreta a sobrecarga de trabalho docente. Zandoná, Cabral e Sulzbach (2014) investigaram como a produção acadêmica na pós-graduação interfere no bem-estar dos docentes brasileiros, compreendendo as consequências do produtivismo para sua saúde. As principais consequências estão relacionadas à Síndrome de Burnout e ao Assédio Moral que docentes podem estar sofrendo, causando doenças psicossomáticas ou apresentando sintomas relacionados a elas.

Café, Ribeiro e Ponczek (2017) analisaram o produtivismo que se apossou das mentes e corpos na pós-graduação brasileira, recorrendo às concepções teóricas de Michel Foucault ao questionarem a disciplinarização dos corpos por meio da imposição de padrões de conduta. A pesquisa, bibliográfica e exploratória, demonstra o surgimento de distorções, inclusive éticas, no processo de construção e difusão de conhecimentos científicos, em razão da avaliação punitiva em detrimento da formativa na apreciação do desempenho dos Programas de Pós-Graduação.

Silveira e Silva (2018), pautando-se no contexto da produtividade acadêmica, analisam materialidades discursivas, discutem a constituição da autoria no interior da ordem do discurso acadêmico, levando em consideração as atuais condições de emergência da autoria, marcadas pelo advento da política produtivista que é levada a cabo pelos órgãos de fomento à pesquisa e pelas Universidades em geral.

Patrus, Dantas, Shigaki (2015) discutiram os impactos do produtivismo na pósgraduação e avaliaram o quanto o produtivismo ameaça a solidariedade acadêmica entendida como um compromisso mútuo entre pesquisadores(as) envolvidos(as) em pesquisa. Os autores (2015) apontam o risco de o produtivismo corroer a solidariedade acadêmica: para eles, não pode existir produtivismo sem colaboração, mas pode haver produtivismo sem solidariedade, o que causa sua alienação, sem a noção de participação em uma comunidade de pesquisadores(as).

Machado, Grosch e Santos (2017) focaram algumas das tensões vivenciadas por professores(as)-pesquisadores(as) vinculados à pós-graduação. Pontuou-se interferência contínua de organismos nacionais de avaliação, regulação, controle, sobretudo por parte da CAPES, na dinâmica de funcionamento das Universidades, o que acaba ferindo a sua autonomia. Prevalece-se a subserviência ao órgão externo, em que professores(as) veemse compelidos a obedecê-lo sob pena de punições, como perda de bolsas, rebaixamento de notas de avaliação do programa etc.

Em síntese, Mortatti (2019, p. 11) traduz a política criticada pelas pesquisas acima citadas em breve revisão da literatura, política que é adotada tanto pela CAPES quanto por demais órgãos nacionais e internacionais de pesquisa, como uma avaliação "quantitativa da qualidade", cujo indicador mais abrangente é a "produtividade acadêmica, [...] pautada em critérios de eficiência e eficácia e medida por meio da relação 'custo x benefícios', ou seja, entre a maior quantidade possível de produtos e resultados e a menor quantidade possível de meios e recursos utilizados para produzi-los".

Feita essa avaliação, aplicam-se premiações aos pesquisadores(as) e/ou PPGs "mais produtivos" e punições aos "improdutivos" ou "menos produtivos". Em outras 
palavras, a produtividade acadêmica em pesquisa tornou-se um critério para atribuição de mérito acadêmico. Então, nascida dessa lógica, deliberadamente capitalista neoliberal, está o que se denomina hoje de "produtivismo acadêmico".

Como ressaltado, o produtivismo acadêmico se refere a um fenômeno subjacente de processos avaliativos que, na verdade, denotam regulação e controle excessivos, conforme também pontuam Costa e Goulat (2018), Mortatti (2019) e outros. Caracteriza-se pela valorização excessiva da quantidade em detrimento da qualidade da produção acadêmica e, no caso nacional, que se deu a partir da implantação do novo modelo de avaliação da pós-graduação pela CAPES.

\begin{abstract}
A análise [do produtivismo] revela a inserção da lógica capitalista que transforma todos os bens materiais e simbólicos em mercadoria. Expressa e exige, no cotidiano do trabalho docente e das universidades, a predominância de uma racionalidade técnica e pragmática, impondo ritmo e organização análogos, por um lado, ao taylorismo-fordismo, mediante uma divisão social do trabalho acadêmico, em uma linha de produção; e, por outro, ao toyotismo, mediante a formação de grupos ou times em várias escalas (grupos de pesquisa, programas de pós-graduação, universidades) que, internalizando mecanismos de controle, dedicam-se a disputar espaços na construção de métricas cada vez mais rigorosas para alavancar seus potenciais competitivos. Enredando docentes e estudantes ao ritmo alucinante de produção alienada social e economicamente, o produtivismo acadêmico alimenta e subordinase a um sistema mundial de produção de conhecimento, no qual aqueles figuram como operários em uma linha de produção (COSTA; GOULAT, 2018, p. 398).
\end{abstract}

E tal mecanismo de avaliação, constituído, por exemplo, pela premiação aos produtivos e punição aos improdutivos, mantém-se atualíssimo. Em 2019, o Ministério da Educação (MEC) anunciou um corte de 5.613 bolsas de pós-graduação da CAPES, justificando-se no que chamou de "contingenciamento". Posteriormente, o MEC informou a reativação de 3.182 bolsas, parte do montante de 5.613. No entanto, como informado, essas bolsas reativadas serão disponibilizadas apenas para Programas de Pós-Graduação de "excelência", com conceito 5, 6 e 7, de acordo com a avaliação da CAPES (ASSOCIAÇÃO BRASILEIRA DAS INSTITUIÇÕES COMUNITÁRIAS DE EDUCAÇÃO SUPERIOR, 2019). Assim, PPGs com conceito 3 (mestrados) e 4 (mestrados e doutorados) serão afetados com a não recomposição de suas bolsas cortadas pelo MEC.

A pesquisa científica no Brasil, portanto, cuja responsabilidade hoje é atribuída às Universidades e, mais especificamente, à pós-graduação, tem seu sentido regido por regra imposta: "Suas etapas têm se invertido, pois aquilo que era consequência da pesquisa (produzir e por onde divulgar o conhecimento) passou a ser fim primeiro (qual periódico pode me dar mais pontuação)". Dessa forma, "aquilo que era fim primeiro da investigação (a descoberta de respostas a problemas que intrigam o pesquisador e por isso o leva a investigar) fica em segundo plano" (SILVA; GONÇALVES-SILVA; MOREIRA, 2014, p. 1429). 
ASSUNÇÃO E POLÍTICA DA CAPES NA AVALIAÇÃO DA PRODUÇÃO DE PESQUISA DA PÓSGRADUAÇÃO NO BRASIL

A incumbência inicial da CAPES em "erradicar" o quadro de professores(as) não titulados que atuavam na Educação Superior, enquanto a pesquisa estava mais a cargo de Institutos do que das Universidades, transformou-se, principalmente, a partir dos Planos Nacionais de Pós-Graduação (PNPGs). Como ressaltam Machado e Bianchetti (2011, p. 248), em pleno regime militar, as Universidades foram surpreendidas com a introdução da pesquisa como atribuição em suas atividades, "[...] quando, subitamente, formar professores para o ensino superior deixou de ser prioritário (meta considerada alcançada) e Programas de Mestrados e Doutorados passariam a formar pesquisadores, em ritmo administrado".

Assim, a avaliação da pós-graduação tornou-se incumbência da CAPES a partir dessa mudança de enfoque, de formação docente à formação para a pesquisa, por intermédio dos PNPGs. Essa mudança de enfoque já pôde ser verificada em decorrência da criação do I Plano Nacional de Pós-Graduação em 1975, em que passou a vigorar o novo sistema de acompanhamento e avaliação da pós-graduação, atribuindo-o como parte das responsabilidades e ações da CAPES.

Todavia, se os primeiros PNPGs demonstram a mudança de enfoque na pósgraduação brasileira, outra legislação, mais recente, demonstra como se deu a instauração da avaliação da CAPES, responsável pelo produtivismo acadêmico. Vosgerau, Orlando e Meyer (2017) analisaram quatro documentos oficiais da CAPES, visando a discutir o impacto do produtivismo acadêmico no desenvolvimento profissional docente. Os documentos selecionados nessa pesquisa são apresentados no Quadro 1.

Quadro 1 - Levantamento dos documentos analisados em relação à CAPES

\begin{tabular}{|l|l|}
\hline Documento & Descrição \\
\hline Decreto n. ${ }^{\circ} 3.860 / 2001$ & $\begin{array}{l}\text { Dispõe sobre a organização do ensino superior, a avaliação } \\
\text { de cursos e instituições, e dá outras providências. Com } \\
\text { atualizações do Decreto. }\end{array}$ \\
\hline Decreto n. ${ }^{\circ} 6.755 / 2009$ & $\begin{array}{l}\text { Institui a Política Nacional de Formação de Profissionais do } \\
\text { Magistério da Educação Básica, disciplina a atuação da } \\
\text { Coordenação de Aperfeiçoamento de Pessoal de Nível } \\
\text { Superior (Capes) no fomento a programas de formação inicial } \\
\text { e continuada, e dá outras providências. }\end{array}$ \\
\hline Decreto n. ${ }^{\circ} 7.692 / 2012$ & $\begin{array}{l}\text { Aprova o Estatuto e o Quadro Demonstrativo dos Cargos em } \\
\text { Comissão da Coordenação de Aperfeiçoamento de Pessoal } \\
\text { de Nível Superior (Capes) e remaneja cargos em comissão. }\end{array}$ \\
\hline $\begin{array}{l}\text { Plano Nacional da } \\
\text { Graduação 2011-2020 }\end{array} \quad \begin{array}{l}\text { O Plano Nacional de Pós-Graduação (PNPG) 2011-2020 tem } \\
\text { como objetivo definir novas diretrizes, estratégias e metas } \\
\text { para dar continuidade e avançar nas propostas para política } \\
\text { de pós-graduação e pesquisa no Brasil. }\end{array}$ \\
\hline
\end{tabular}

Fonte: Vosgerau, Orlando e Meyer (2017). 
O primeiro documento analisado pelos autores (2017), o Decreto n. ${ }^{\circ} 3.860$, que dispõe sobre a organização da Educação Superior e a avaliação de cursos e instituições, determina, entre seus critérios, a produção acadêmica, tecnológica e cultural e as condições de trabalho e qualificação docente, além de reafirmar a CAPES como responsável pela a avaliação da pós-graduação. O segundo documento, o Decreto n. ${ }^{\circ}$ 6.755/2009, institui o Plano Nacional de Formação de Professores de Educação Básica (PARFOR), atribuindo-o à CAPES, que aponta para o fortalecimento da formação docente e do ingresso em cursos de especialização, mestrado ou doutorado. $O$ terceiro documento trata do Decreto . $^{\circ}$ 7.692/2012, que retoma a finalidade inicial da CAPES, reafirmando sua finalidade em subsidiar, além do desenvolvimento científico, a formação de profissionais para a Educação Básica e Superior, cabendo à CAPES a definiç̧ão de padrões de qualidade para regular os cursos de pós-graduação stricto sensu do país. Referente ao quarto e último documento analisado, ressalta-se antes que, ao todo, são seis os Planos Nacionais de Pós-Graduação.

Enquanto o primeiro PNPG (1975-1979) institucionalizava a pesquisa como atividade regular nas Universidades, nos planos seguintes priorizou-se a questão da sua avaliação. Hostins (2006, p. 151) ressalta a ruptura na avaliação adotada pela CAPES após 1998, ano em que a avaliação voltou-se para a promoção da competição entre os PPGs: “Para impulsionar a internacionalização é necessário induzir os Programas à competitividade, à inovação e ao empreendedorismo, tal como funciona a lógica do setor corporativo empresarial" (HOSTINS, 2006, p. 151).

No último dos PNPGs, referente ao período de 2011-2020, e analisado por Vosgerau, Orlando e Meyer (2017), intensifica-se a lógica do produtivismo. O PNPG chega a citar o produtivismo, a sobreposição quantitativa sobre a qualidade das produções, como uma imperfeição que requer melhoria. Entretanto, mesmo que reconheça isso, não há qualquer perspectiva de que possa alterá-lo.

Nesse sentido, embora pesquisadores(as) apontem para a necessidade da formação docente na pós-graduação, a política implementada pela CAPES colabora para que seja reconhecida apenas a capacidade de produção científica, sendo esse "[...] o critério que impera nos processos de seleção e avaliação de desempenho de professores universitários, assim como na avaliação de cursos de graduação, das IES e programas de pós-graduação" (VOSGERAU; ORLANDO; MEYER, 2017, p. 244).

Contudo, como argumentam Machado e Bianchetti (2011, p. 248), essa política foi imposta arbitrariamente, "o terreno não foi preparado para a implementação dessas mudanças na época em que se fizeram sentir nas universidades [...]. Dessa forma, dispositivos de controle, premiação e punição foram implementados, transformando a indução em camisa de força". Os resultados disso são vistos hoje, com o domínio do produtivismo e a subserviência aos critérios de avaliação externa. Em visão pouco otimista, os autores seguem ressaltando que:

Aos pesquisadores, resta integrar a força-tarefa da máquina científica e produzir, alienados do exercício da crítica e excluídos das decisões que controlam a ciência, a universidade, seu próprio cotidiano e a humanidade. O produtivismo acadêmico, na materialidade do paper foi erigido a fetiche-mercadoria-conhecimento e, em ritmo de Tempos Modernos, transformou os intelectuais em estressados, medicados, eficientes operários de alto padrão, seres 'sem tempo' 
para a principal atribuição: analisar com rigor crítico a complexidade dos processos em curso (naturais ou sociais), possibilitando descortinar a lógica subjacente que comanda o espetáculo da história (MACHADO; BIANCHETTI, 2011, p. 151, grifos dos autores).

Revisitada a trajetória da CAPES na avaliação da produção de pesquisa da pósgraduação no Brasil e o desenvolvimento de sua atual política, acusada de produtivista, há de se apontar para a influência neoliberal à qual essa política se submete. Ferreira (2015, p. 14) esclarece que a institucionalização da pesquisa ocorreu em concomitância à chegada do gerencialismo no Brasil, "modelo de gestão baseado no neoliberalismo, submetendo-se aos moldes comércio-empresa e trazendo à tona conceitos como 'eficiência' e 'produtividade'. A ideologia neoliberal avançou na área acadêmica [...] ao adotar 'ferramentas' da gestão empresarial".

Logo, as Universidades têm aproximado sua estrutura e funcionamento aos das empresas. Salvá (2015) ainda ressalta que as novas tecnologias de comunicação e informação possibilitaram a execução de tarefas excedentes fora do ambiente de trabalho por aqueles que não conseguem atingir uma boa pontuação QUALIS, para atenderem aos critérios da avaliação da CAPES, em meio ao medo da desqualificação e exclusão, o que acaba gerando os problemas do produtivismo citados anteriormente.

Debruçando-se sobre a política da CAPES, além do número de trabalhos produzidos, a qualidade dessas produções é atestada por intermédio de medidas bibliométricas, com destaque para o fator de impacto de periódicos científicos (número de citações de artigos de uma revista indexada em outros periódicos também indexados), se os resultados de pesquisa forem divulgados em artigos, e para o Índice $H$ do pesquisador (quantidade de artigos publicados por um autor e quantidade de vezes que cada um deles for citado). Além do fator de impacto, a CAPES conta com uma classificação própria para as produções: $\mathrm{O}$ Webqualis. Essa forma de avaliação estratifica os periódicos, classificando-os em A1, A2, A3, A4, B1, B2, B3 e B43.

A partir dessa classificação, a CAPES atribui um valor quantitativo aos artigos publicados nos periódicos então estratificados. Traz-se, ao âmbito acadêmico, princípios nitidamente característicos do sistema capitalista, "em que o fator de impacto do periódico e/ou Webqualis se torna moeda corrente para uma demanda cada vez maior de pesquisadores dispostos a alcançá-los" (SILVA; GONÇALVES-SILVA; MOREIRA, 2014, p. 1428). Em outras palavras, as produções acadêmicas tornam-se um tipo de capital.

A idéia de que um cientista que publica duas vezes mais artigos que outro é duas vezes mais produtivo, sem levar em conta a qualidade das obras, é chocante mesmo para o mais elementar senso comum. Essa contradição não é ignorada e motiva a elaboração de formas mais sofisticadas de avaliação, como a que leva em conta o número de citações que cada publicação recebe na literatura especializada. Mas, ainda nesse caso, a ênfase é não apenas no aspecto quantitativo, mas também no requisito de que as quantidades envolvidas devem ser mensuráveis de forma inteiramente objetiva. É difícil explicar de outra maneira tal diretriz, a não ser como um recurso para encaixar a 
força o conhecimento científico no molde da mercadoria (OLIVEIRA, 2006, p. 252-253).

Em termos acadêmicos, produzir significa publicar e, no caso, publicar resultados de pesquisas científicas. Assim, como esclarece Mortatti (2019, p. 11, grifos da autora), esse tipo de produção acadêmica deve resultar de pesquisas científicas "desenvolvidas por meio de métodos científicos com finalidade de produção de conhecimento científico"e a única justificativa para seu desenvolvimento deve ser a necessidade de "compreender e solucionar problemas, cuja relevância científica e social se sobreponha aos interesses pessoais e políticos de pós-graduandos e seus orientadores, de gestores da universidade e [...] responsáveis pela implementação de políticas públicas". Dessa forma, outras não podem ser suas finalidades, "as quais devem pautar a definição de sua qualidade e dos critérios e meios para avaliá-la, bem como o necessário e almejado impacto científico e social" (p. 11). Logo, a publicação deve se pautar única e inequivocamente na intenção de divulgar resultados de pesquisas e não na geração de pontuação para que pesquisadores(as) obtenham fomento de agências, prestígio ou qualquer outro interesse pessoal e/ou político, os quais podem até existir, desde que secundários ao primeiro. No entanto, ainda que a crítica a esse status quo exista, sendo aqui revisitada, a tendência atual é de aderir ao produtivismo, inclusive por parte de quem o critica. Nas palavras de Machado e Bianchetti $(2011$, p. 2), "o trabalhador-pesquisador reclama fazer mais do que quer ou pode. Critica, porém acata".

\section{A PRODUÇÃO EM PERIÓDICOS DE UM PROGRAMA DE PÓS-GRADUAÇÃO EM EDUCAÇÃO: MAPEAMENTO E ANÁLISE}

Apresentam-se agora os resultados de uma investigação que levantou as publicações em periódicos (artigos) do corpo docente de um Programa de Pós-Graduação stricto sensu da área de Educação. Conforme já ressaltado, utilizou-se dos critérios de área e conceito do Programa, respectivamente, da área de Educação e com conceito CAPES acima da média (conceito 4), além de se ter delimitado a investigação à produção em periódicos, visto que outras formas de publicação, como livros, capítulos de livros, posters, resumos e trabalhos em anais de eventos também compõem a produção acadêmica da pesquisa científica.

O Programa investigado conjuga, atualmente, um corpo docente que totaliza um número superior a 30 docentes $^{4}$, que, por sua vez, distribuem-se em cinco linhas de pesquisa, de acordo com a(s) temática(s) envolvida(s) no seu escopo de pesquisa. Dessa forma, os(as) candidatos(as) que prestam o processo seletivo para possível ingresso no PPG escolhem uma das cinco linhas e, na etapa de final da seleção, os(as) docentes de cada linha os(as) selecionam entre aqueles(as) que prestaram na sua respectiva. Ou seja, entre os candidatos(as) que tenham interesse, já manifestado em seu projeto de pesquisa, de desenvolver o mestrado ou o doutorado dentro de seu escopo.

O levantamento das publicações dos(as) docentes foi feito trabalhando-se com os dados disponibilizados na plataforma Currículo Lattes de cada um(a). Considerando o período delimitado de 2000 a 2018, o total de artigos publicados pelos docentes do Programa foi de 1.641. Por linha, a distribuição desse montante fica a seguinte: linha A: 
399 artigos; linha B: 456 artigos; linha C: 294 artigos; linha D: 216 artigos; e linha E: 276 artigos. A média de artigos publicados por linha é de 328 , ainda assim, segundo os dados anteriores, já pode-se inferir a existência de linhas mais produtivas e linhas menos produtivas, o que, segundo Salvá (2015), é um critério considerado pela CAPES na avaliação da produção do Programa e atribuição de seu conceito Qualis. Para se medir a progressão da produção em periódicos do Programa ao longo dos anos, dentro do período delimitado, e compará-la com a conjuntura de implementação da política produtivista da CAPES, elaborou-se o seguinte gráfico disposto na Figura 1 abaixo.

Figura 1 - Relação da produção de artigos científicos publicados em periódicos pelos docentes do Programa investigado no período de 2000 a 2018

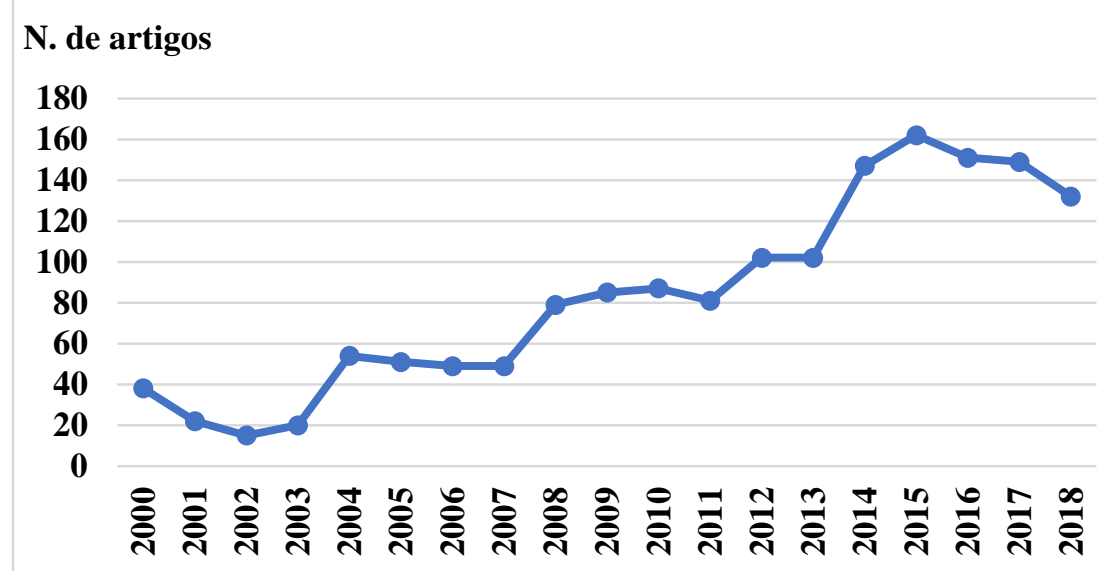

Fonte: Elaborado pelo autor

Observa-se que, no período de 15 anos, de 2000 a 2015, houve um aumento significativo na produção levantada, cerca de $400 \%$, quadriplicando a produção, que foi de 38 artigos publicados nesse ano inicial a 162 artigos publicados no ano final. $O$ intervalo entre 2013 e 2015 ilustra em um curto período de tempo (03 anos) essa tendência de aumento na produção, com 102 artigos publicados no ano de 2013 para 162 artigos publicados no ano de 2015, ou seja, um aumento de pouco mais de $50 \%$ na produção. Após 2015, observa-se uma pequena diminuição na produção, de 162 em 2015 para 132 artigos em 2018, porém, ainda assim, mantém-se a produção acima do seu número inicial em 2000.

Tal resultado é preocupante e vai ao encontro da atual tendência de se aderir ao produtivismo acadêmico a fim de se obter as premiações reservadas aos(às) mais produtivos(as), bem como de livrar-se das punições dadas aos(às) improdutivos(as). Como se viu recentemente, por parte do Ministério da Educação (MEC) no episódio de "contingenciamento" já mencionado, "avalia-se o desempenho dos programas de pósgraduação durante um espaço temporal e, caso os mesmos não tenham atingido os índices esperados pela agência, há aplicações de sanções como forma de punição" (CAFÉ; RIBEIRO; PONCZEK, 2017, p. 84). 
Dispondo-se dos documentos oficiais da CAPES analisados por Vosgerau, Orlando e Meyer (2017), não há, à primeira vista, uma relação tão direta, considerando-se a data de publicação de cada um deles e o número de artigos publicados pelo PPG nesses anos e na passagem entre eles, isto é, as implicações desses documentos não ocorrem imediatamente no ano seguinte de sua publicação. Contudo, sob um olhar mais abrangente, infere-se que há sim uma relação direta e explícita com a postura e política da CAPES na avaliação da produção da pós-graduação brasileira, já que o aumento da produção do PPG analisado, ao longo dos anos, justificaria essa relação com o campo normativo da pós-graduação.

Fazia-se pesquisa em 2000 como se faz pesquisa hoje em 2020. Então, por que aumentou tanto a produção de artigos? Pode-se pensar, num primeiro momento, na expansão da pós-graduação no Brasil e fatores relacionados, porém os dados aqui apresentados tratam de um mesmo Programa de Pós-Graduação, o que não possibilitaria aplicar essa explicação assim tão facilmente.

Mortatti (2019) chamou a atenção para, como parte do produtivismo, a preocupação de se obter a maior quantidade possível de produtos (artigos) com a menor quantidade possível de meios e recursos utilizados para produzi-los (tanto de financiamento quanto de pesquisas): se uma pesquisa de mestrado ou doutorado antes resultava em um ou dois artigos, hoje busca-se produzir, a partir dessa mesma pesquisa, meia dúzia de artigos ou mais. Ou seja, fragmentam-se os resultados obtidos com uma pesquisa original (tratada numa dissertação ou tese, por exemplo) em vários pedaços, constituindo a partir disso vários artigos. Essa é uma possível explicação do resultado encontrado na qual tendo a acreditar.

Diante desse resultado, procurou-se verificar se o mesmo fenômeno, a evidenciação do produtivismo acadêmico, com o passar dos anos, também ocorreu distribuindo a produção segundo as linhas de pesquisa que compõem o PPG investigado. Se isso ocorreu em todas ou se em alguma se diferiu. A Figura 2, a seguir, trata da produção em periódicos dos(as) docentes separadamente, segundo as cinco linhas referidas, como linha $A, B, C, D$ e E.

Figura 2 - Relação da produção de artigos científicos publicados em periódicos segundo as linhas do Programa investigado no período de 2000 a 2018

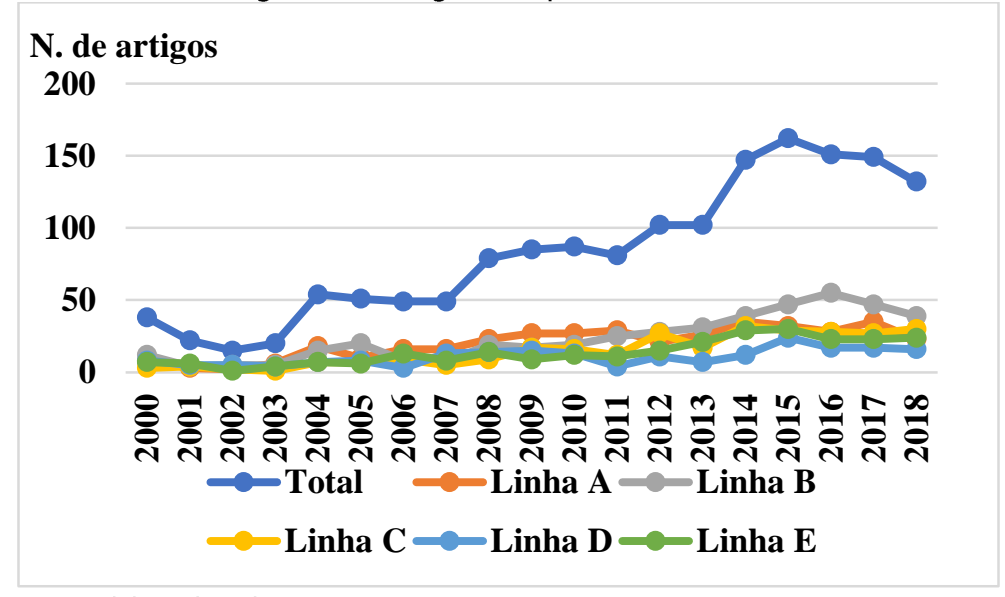

Fonte: Elaborado pelo autor 
Observa-se que o aumento da produção de 2000 a 2018, de fato, repete-se, ainda que algumas linhas, como a linha $C$ e a linha $D$, demonstrem mais instabilidade nessa progressão do que as outras. A linha que se destaca na produção é a linha $B$, com um aumento quase contínuo em todo o período, decaindo, assim como as demais (e a produção de todo o Programa), a partir do ano de 2014, embora também permaneça com número superior ao do ano inicial calculado de 2000. Além disso, dos anos de 2013 a 2015, fica evidente o salto em um curto período de tempo dado na produção de um modo geral, tanto individualmente pelas linhas quanto pelo Programa em geral, como sinalizado no gráfico anterior e aqui em comparação com as cinco linhas.

A competitividade entre PPGs é consciente pelo mecanismo de avaliação institucional, como trata Hostins (2006). Não tão dificilmente essa lógica de competição pode ser introjetada pelos Programas internamente, entre linhas e até entre docentes em específico. Esse dado aqui apresentado seria "perigoso" caso caísse nas "mãos erradas", pois, pode-se recorrer a ele para justificar políticas gerencialistas (FERREIRA, 2015) e cobrar dos próprios membros do Programa, sejam pessoas ou órgãos externos, maior produção, comparando-se o desempenho de determinada linha ou docente, sendo que isso já ocorre entre PPGs.

O novo dado não apresenta muita diferenciação em relação ao dado anterior, referente à produção de todo o Programa. Os aumentos, constâncias e quedas no número de publicação não chegam a ser contrastantes, resultando no estado atual (produção do ano de 2018) melhor, em termos quantitativos, que o estado anterior (produção de 2000) da produção investigada.

\section{CONSIDERAÇÕES FINAIS}

Buscou-se, neste artigo, tratar dos efeitos do produtivismo na produção de um PPG em Educação eleito aleatoriamente, dentro do critério de pontuação da Capes 4. Os resultados foram surpreendentes e superaram a hipótese levantada: constatou-se o aumento na produção de pesquisa investigada, que chegou a $400 \%$ em 15 anos, quadruplicando-se em relação ao primeiro ano contabilizado. Esse resultado ajusta-se ao que a literatura diz sobre o produtivismo acadêmico e a situação atual da pesquisa científica no Brasil, pautada pela política neoliberal.

A revisão bibliográfica feita também possibilitou o encontro de ideias que estão sendo disseminadas em tempo recente - a maioria da bibliografia data de 2010 a 2019-, mas que seguem esquecidas nos corredores das Universidades. Ainda que exista a crítica ao modelo, a adesão à política produtivista imposta é superior à resistência e, infelizmente, pode partir inclusive daqueles(as) que tecem críticas ao status quo da academia. No fim, critica-se, mas acata-se, como pontuaram Machado e Bianchetti (2011), por medo das sanções.

Embora sejam inegáveis os esforços da CAPES e sua contribuição para o avanço da pós-graduação no Brasil, aponta-se para as modificações que precisam ser feitas nos critérios utilizados para avaliação dos Programas de Pós-Graduação. Eles deveriam ser fruto de muita reflexão e diálogo em conjunto com as Universidades, demais instituições 
de Educação Superior, agências de fomento etc, levando-se em conta as especificidades de cada área de conhecimento, seus objetivos e seu papel social.

Ademais, com a investigação tratada neste artigo que aqui se encerra, tentou-se preencher uma lacuna na literatura pertinente que ainda carece de levantamentos sobre a produção de pesquisa em diversos contextos, outras áreas de conhecimento ou qualquer enfoque em que seja possível aplicar uma análise crítica da produção da pesquisa científica. Portanto, essa lacuna que só poderá ser preenchida de fato com mais estudos subsequentes, além de também serem necessárias novas reflexões sobre a problemática do produtivismo e seus efeitos maléficos, tanto no aumento da produção tal como aqui se trouxe -, que pode ser de qualidade duvidosa, quanto nos efeitos na rotina de trabalho, saúde mental e bem-estar do(a) docente-pesquisador(a).

Artigo recebido em: 03/12/2019

Aprovado para publicação em: 05/03/2020

\section{"PUBLISH OR PERISH": EFFECTS OF ACADEMIC PRODUCTIVITY ON JOURNAL PRODUCTION IN A GRADUATE EDUCATION PROGRAM (2000-2018)}

ABSTRACT: In this article, through a bibliographic review, the possible effects generated by academic productivism on the production in journals of a Postgraduate Program in Education are investigated. The current state of Brazilian research production was considered, which tends to adhere to academic productivism and to the training of the researcher at the expense of the training of the university professor. The investigation was delimited by choosing, by the defined criteria, a Postgraduate Program in the Education area with a CAPES concept above 4 and, to measure the effects of productivism, the production in journals of the faculty of this Program was raised considering the period from 2000 to 2018. There are, in fact, effects on the production of the Program, with a very significant increase and which is related to the assumption and policy of CAPES in the evaluation of graduate studies.

KEYWORDS: Productivism. Postgraduate studies. Academic production.

\section{"PUBLICAR O PERECER": EFECTOS DE LA PRODUCTIVIDAD ACADÉMICA EN LA PRODUCCIÓN DE REVISTAS EN UN PROGRAMA DE EDUCACIÓN DE POSGRADO (2000-2018)}

RESUMEN: En este artículo, a través de una revisión bibliográfica, se investigan los posibles efectos que genera el productivismo académico en la producción en revistas de un Programa de Posgrado en Educación. Se consideró el estado actual de la producción investigadora brasileña, que tiende a adherirse al productivismo académico ya la formación del investigador a expensas de la formación del profesor universitario. La investigación se delimitó eligiendo, por los criterios definidos, un Programa de Posgrado en el área de Educación con un concepto CAPES por encima de 4 y, para medir los efectos del productivismo, se planteó la producción en revistas de la facultad de este Programa considerando el período de 2000 a 2018. De hecho, existen efectos en la producción del Programa, con un incremento muy significativo y que está relacionado con el supuesto y política de CAPES en la evaluación de estudios de posgrado.

PALABRAS CLAVE: Productivismo. Posgraduación. Producción académica. 


\section{NOTAS}

1) Considerando-se, no âmbito acadêmico, as implicações desse mecanismo de avaliação no trabalho e na saúde de docentes universitários e de pós-graduandos(as), conforme demonstram várias pesquisas (MACHADO; BIANCHETTI, 2011; FERREIRA, 2015; SALVÁ, 2015; PAIVA, 2016).

2) A CAPES realiza periodicamente uma avaliação geral da pós-graduação brasileira. Nesse processo, que envolve PPGs de todo o país, a avaliação concentra-se na análise comparativa da evolução e do estado da arte em cada área que os Programas avaliados se vinculam, distribuindo-os segundo os conceitos 3 (regular), que adverte padrão mínimo de qualidade, 4 (bom), 5 (muito bom), padrão nacional de excelência, e, em destaque, os últimos conceitos, 6 e 7 , de excelência internacional e de referência para suas respectivas áreas.

3) Essa estratificação passou por modificações na última avaliação da CAPES, dispondo aqui a mais recente.

4) Não será revelado o número exato de docentes do Programa para fins de anonimato, que por aqui identificar ser superior a 30 docentes, pode também ser superior a 40, 50 etc. Ressalta-se, também, que a delimitação temporal de 2000-2018 foi feita considerando que esse se tratou de um período considerável para o desenvolvimento da avaliação da CAPES, sendo que o período de existência do PPG é superior a ele, embora não se identifique aqui o quanto.

\section{REFERÊNCIAS}

ASSOCIAÇÃO BRASILEIRA DAS INSTITUIÇÕES COMUNITÁRIAS DE EDUCAÇÃO SUPERIOR. Capes anuncia corte de $\mathbf{5 . 6 1 3}$ bolsas de pós-graduação para este ano. 2019. Disponível em: https://www.abruc.org.br/atualidade/noticia/capes-anuncia-corte-de5613-bolsas-de-posgraduacao-para-este-ano. Acesso em: 19 jan. 2020.

CAFÉ, Anderson Luis da Paixão. RIBEIRO, Núbia Moura. PONCZEK, Roberto Leon. A fabricação dos corpos dóceis na pós-graduação brasileira: em cena o produtivismo acadêmico. Encontros Bibli, v. 22, n. 49, p. 75-88, maio/ago., 2017.

COSTA, Camila Furlan da; GOULART, Sueli. Capitalismo acadêmico e reformas neoliberais no ensino superior brasileiro. Cad. EBAPE.BR, v. 16, n. 3, Rio de Janeiro, p. 396-409, jul./set., 2018.

FERREIRA, Carla Guimarães. Percepções dos docentes avaliados pela coordenação de aperfeiçoamento de pessoal de nível superior (CAPES): um estudo sobre o produtivismo acadêmico. 2015. 175 f. Dissertação (Mestrado em Administração), Universidade Federal Fluminense (UFF), Niterói, 2015.

HOSTINS, Regina Célia Linhares. Os Planos Nacionais de Pós-graduação (PNPG) e suas repercussões na pós-graduação brasileira. Perspectiva, Florianópolis, v. 24, n. 1, p. 133 160, 2006. 
“Publique ou pereça”: efeitos do produtivismo...

Dossiê 622

KUENZER, Acacia Zeneida; MORAES, Maria Célia Marcondes de. Temas e tramas na pósgraduação em educação. Educação e Sociedade, Campinas, v. 26, n. 93, p. 1341-1362, set./dez., 2005. 
SILVA, M. E. F. da

MACHADO, Ana Maria Netto; BIANCHETTI, Lucídio. (Des)fetichização do produtivismo acadêmico: desafios para o trabalhador-pesquisador. RAE-Revista de Administração de Empresas, v. 51, n. 3, p. 244-254, 2011.

MACHADO, Ana Maria; GROSCH, Maria Selma; SANTOS, Vanice dos. Regulação e controle na pós-graduação: do produtivismo acadêmico à noção de excelência com pertinência territorial. Conjectura: Filos. Educ., Caxias do Sul, v. 22, n. 1, p. 52-68, jan./abr., 2017.

MORTATTI, Maria do Rosário Longo. Em tempos sombrios, a produção acadêmica brasileira sobre alfabetização: avaliação da qualidade e impacto científico e social. Laplage em Revista, Sorocaba, v. 4, n. 2, p. 8-26, maio/ago., 2018.

MOTTA-ROTH, Désirée; HENDGES, Gabriela Rabuske. Produção textual na universidade. São Paulo: Parábola Editorial, 2010.

OLIVEIRA, Marcos Barbosa de. Desmercantilizar a tecnociência. In: SANTOS, Boaventura de Souza (Org.). Conhecimento prudente para uma vida decente: um discurso sobre as ciências revisitado. São Paulo: Cortez, 2006.

PAIVA, Janaína Zildéia da Silva. As transformações do trabalho docente na universidade federal do amazonas: da produção ao produtivismo na pós-graduação. 2016. 167 f. Dissertação (Mestrado em Serviço Social) - Universidade Federal do Amazonas (UFAM), Manaus, 2016.

PATRUS, Roberto; DANTAS, Douglas Cabral; SHIGAKI, Douglas Cabral. O produtivismo acadêmico e seus impactos na pósgraduação stricto sensu: uma ameaça à solidariedade entre pares?. Cad. EBAPE.BR, Rio de Janeiro, v. 13, n. 1, jan./mar., 2015.

SALVÁ, Maria Nair Rodrigues. Reflexos da Avaliação Capes no Trabalho Docente de PósGraduação Stricto-sensu no Campo da Saúde Coletiva. Revista Cadernos de Estudos Sociais e Políticos, v. 4, n.7, p. 20-43, jan./jun., 2015.

SILVA, Junior Vagner Pereira da; GONÇALVES-SILVA, Luiza Lana; MOREIRA, Wagner Wey. Produtivismo na pós-graduação. Nada é tão ruim, que não possa piorar. É chegada a vez dos orientandos!. Movimento, Porto Alegre, v. 20, n. 4, p. 1423-1445, out./dez., 2014.

SILVEIRA, Éderson Luís; SILVA, Francisco Vieira da. Cão que lattes não morde? Efeitos do produtivismo acadêmico na construção da autoria. Macabéa - Revista Eletrônica do Netlli, v. 7, n. 1, p. 127-136, jan./jun., 2018.

VOSGERAU, Dilmeire Sant'Anna Ramos; ORLANDO, Evelyn de Almeida; MEYER, Patricia. Educ. Soc., Campinas, v. 38, n. 138, p. 231-247, jan./mar., 2017. 
"Publique ou pereça": efeitos do produtivismo...

Dossiê 636

Matheus Estevão Ferreira da Silva: Pedagogo (2018) pela Faculdade de Filosofia e Ciências (FFC/UNESP) de Maŕlia, Mestrando em Educação pelo Programa de PósGraduação em Educação (PPGE) (Conceito CAPES 6) da mesma instituição e graduando em Psicologia pela Faculdade de Ciências e Letras (FCL/UNESP) de Assis. Foi Visiting Student Researcher na San Diego State University (SDSU) e estudante emérito da Embassy English (San Diego, Califórnia, EUA), pelo programa do Centro Paula Souza.

Orcid: https://orcid.org/0000-0002-2059-6361

E-mail: matheus.estevao2@hotmail.com

Este periódico utiliza a licença Creative Commons Attribution 3.0, para periódicos de acesso aberto (Open Archives Iniciative - OAI). 